\title{
TWITTER Y EL DEBATE SOBRE LA RESPONSABILIDAD SOCIAL EMPRESARIAL: ANALIZANDO EL POSICIONAMIENTO PÚBLICO DE NIKE CONTRA EL RACISMO ESTRUCTURAL
}

\author{
Coraima Santana González \\ Universidad de La Laguna \\ csantanaglez@gmail.com
}

\section{RESUMEN}

El análisis de redes se ha convertido en las últimas décadas en un elemento importante para comprender las dinámicas sociales. En este sentido, la investigación pretende conocer en qué medida las prácticas de responsabilidad social empresarial (RSE) de Nike se reflejan en las estructuras conversacionales de las redes sociales virtuales. Para ello se comparan los posicionamientos públicos de Nike y Adidas contra el racismo en EE. UU. El principal hallazgo alude a las diferencias estructurales y conversacionales que las redes Nike y Adidas presentan en Twitter. Esta aplicación metodológica supone una novedad, ya que permite dar un salto cualitativo y cuantitativo en los estudios sociológicos del consumo.

Palabras Clave: redes sociales, responsabilidad social empresarial, racismo, twitter.

TWITTER AND THE CORPORATE SOCIAL RESPONSIBILITY DEBATE: ANALYZING NIKE'S PUBLIC STANCE AGAINST STRUCTURAL RACISM

\section{Abstract}

In recent decades, network analysis has become an important element in understanding social dynamics. In this sense, the research aims to understand to what extent Nike's Corporate Social Responsibility (CSR) practices are reflected in the conversational structures of virtual social networks. The main finding refers to the structural and conversational differences that the Nike and Adidas networks present on Twitter. This methodological application is a novelty, as it allows a qualitative and quantitative leap in the sociological studies of consumption.

KEYwORDS: social networks, corporate social responsibility, racism, twitter. 


\section{INTRODUCCIÓN}

Esta investigación tiene como propósito conocer, mediante un estudio de caso, cuáles son las estrategias y los debates surgidos en torno a la responsabilidad social empresarial (RSE). Con el paso de los ańos, los consumidores han incrementado sus expectativas sobre las implicaciones sociales y medioambientales de las empresas. Establecer una RSE se convierte, por tanto, en una estrategia que permite mejorar la imagen, la reputación y la lealtad corporativa, además de contribuir al posicionamiento de las marcas (Niño-Benavides \& Cortés, 2018).

Por esta razón, el estudio pretende conocer el impacto mediático que ha tenido para Nike el posicionarse contra el racismo en EE. UU. La multinacional ya contaba con una larga trayectoria de posicionamientos en asuntos controvertidos, como son los derechos LGTBIQ, el racismo o el sexismo, entre otros (NIKE. Inc, 2021b). Sin embargo, uno de los temas más reiterados en sus últimas campañas ha sido el apoyo al movimiento Black Lives Matter (BLM), en la lucha contra el racismo estructural $^{1}$ (De la Vega Martínez, 2020). Por tanto, al posicionarse recurrentemente y elaborar iniciativas a largo plazo como parte de su programa, la empresa logra mantener una imagen de responsabilidad hacia los consumidores (Heffron, 2019). Esto genera a su vez un impacto mediático que afecta directamente a la empresa y sus estrategias de marketing. En este sentido, se concentran las opiniones sobre la responsabilidad de la marca en las redes sociales.

En particular, los datos se extrajeron durante los disturbios contra el racismo en varias ciudades estadounidenses y la sentencia del caso George Floyd. Tales circunstancias arrastraban una oleada de reivindicaciones sobre las poblaciones vulneradas, la discriminación vertical y la legitimización del abuso de poder (Inofuente Peñaloza et al., 2021). Tras el asesinato de George Floyd todos estos patrones se visibilizaron a nivel internacional, generando un alzamiento de la consigna BLM. Por ello, el contexto donde se desenvuelven los debates es importante para el estudio de caso. En tal sentido, Nike no ha sido la única marca deportiva en opinar ante esta situación. De hecho, su principal competidor, Adidas, también se ha posicionado en diversas ocasiones en contra del racismo. A modo de ejemplo, uno de los Tuits de Adidas en apoyo al BLM logró dejar a un lado las diferencias entre ambas firmas, al compartir la campaña de Nike: Until We All Win. En consecuencia, estudiar de forma comparativa ambos casos permite comprender el grado de aceptación de Nike como empresa responsable en las redes sociales virtuales.

${ }^{1}$ El racismo estructural debe comprenderse como un modo de violencia que se genera en el tejido social mediante las formas institucionales y culturales. Adopta la forma institucional en la medida en la que se aplican las decisiones del grupo dominante y cultural cuando se difunden comportamientos y actitudes discriminatorias (Batista, 2018). 


\section{OBJETIVOS E HIPÓTESIS}

El objetivo principal de este estudio se basa en conocer si las redes de Nike y Adidas mantienen estructuras conversacionales diferenciadas en Twitter, según su implicación en la responsabilidad social empresarial.

Entre los objetivos específicos se encuentran:

Analizar las bases de la responsabilidad social empresarial (RSE).

a. Conocer las principales aportaciones y debates teóricos sobre la RSE.

b. Analizar las estrategias de Nike para la inclusión social en el deporte, prestando especial atención a sus mecanismos contra el racismo estructural.

Comparar las características estructurales de las redes a partir de las menciones y respuestas a@Nike y su competencia@Adidas en Twitter.

a. Analizar el grado de centralidad de las redes.

b. Conocer las diferencias estructurales y conversacionales de las redes.

c. Identificar las diferencias estructurales de las zonas de mayoría republicana y demócrata en EE. UU. para ambas redes.

Hipótesis 1. Nike y Adidas tienen estructuras de redes conversacionales distintas.

Los debates públicos en materia de responsabilidad social han generado que la red Nike tenga mayor centralidad estructural que la red Adidas.

Hipótesis 2. Las comunidades internas que conforma la red Nike están categorizadas por mensajes que apelan a la responsabilidad social de la marca. Mientras que en las comunidades de Adidas son más populares los mensajes sobre sus productos y campañas publicitarias.

Hipótesis 3. Las estructuras de las comunidades internas de la red Nike y la red Adidas variarán según la geolocalización desde donde se emitió el Tuit. Las estructuras de los estados republicanos estadounidenses serán diferentes a los estados demócratas para las redes Nike y Adidas.

En adelante, la investigación se estructura de la siguiente manera: en primer lugar, se abordan las bases teóricas de la responsabilidad social empresarial. Seguidamente se estudia el caso Nike de forma comparativa con el de Adidas. Además, se analizan las interacciones en los perfiles de @Nike y @Adidas en Twitter mediante los softwares NodeXL Pro y SPSS. Así mismo, se examinan las diferencias estructurales y conversacionales de ambas empresas. Para finalizar, se considera si además existen distinciones según la influencia política de los estados demócratas y republicanos desde donde se emitieron y recibieron los Tuits. 


\section{LOS INICIOS DE LA ECONOMÍA SOCIAL}

A partir de los años 90, las prácticas económicas volvieron a los valores de responsabilidad y de confianza, los cuales se habían establecido en el imaginario social de las empresas, previas al capitalismo salvaje (Pintos, 2004). Es aquí donde surgen los conceptos de economía social y RSE (Alberich, 2014). En la economía social, el ser humano prima sobre el capital; por tanto, las iniciativas parten de la solidaridad. En ella, las organizaciones, productores y consumidores participan en las tomas de decisiones siguiendo con sus principios democráticos. Sin embargo, esta postura genera una doble lectura, pues aceptar la RSE sería una forma de humanizar el capitalismo financiero, de aprobar la acumulación de riquezas y los sistemas de dominación, siempre y cuando dicha explotación esté en niveles aceptables y sostenibles. Para no caer en eso, el desarrollo debía velar por la justicia y el bien común. Por consiguiente, las empresas empezaron a considerar las reclamaciones ciudadanas y a debatir sobre la RSE (Vargas, 2006).

\section{LA RESPONSABILIDAD SOCIAL EMPRESARIAL Y SUS PLANTEAMIENTOS TEÓRICOS}

Según la definición del Libro Verde, la RSE debe comprenderse como

La integración voluntaria, por parte de las empresas, de las preocupaciones sociales y medioambientales en sus operaciones comerciales y sus relaciones con el entorno. Ser socialmente responsable no significa solamente cumplir a plenitud las obligaciones jurídicas, sino también ir más allá de su cumplimiento invirtiendo más en el capital humano, el entorno y las relaciones con los interlocutores (Comisión de las Comunidades Europeas, 2001, p. 7)Affirmation of the Consequent «AC».

Sin embargo, frente a esta definición genérica se debe matizar que la RSE es un concepto que conlleva debates teóricos contrapuestos. Pues por un lado, el término surge como un rechazo al comportamiento empresarial ortodoxo basado en la maximización de beneficios (Cea Moure, 2010). Mientras que por otro, contribuye a esta visión neoclásica al vincular el éxito competitivo con las intervenciones en las necesidades sociales existentes (Vázquez-Rueda et al., 2019). Desde esta perspectiva, la RSE genera a largo plazo beneficios en el rendimiento y valor empresarial reduciendo riesgos y favoreciendo su reputación (Vargas, 2006).

A partir de la segunda mitad del siglo xx, el concepto de RSE se ha desarrollado según los cambios sociales, medioambientales, políticos y económicos en los que intervienen las empresas. Como consecuencia, estas han desplazado la idea clásica de empresa unitaria, donde la responsabilidad prevalece en los accionistas, hacia una empresa pluralista, en la que los distintos grupos de interés se responsabilizan en la buena marcha del negocio (Cea Moure, 2010). No obstante, se debe matizar que la RSE no es lo mismo que la ética empresarial. La responsabilidad Social es un elemento interno de la ética de las empresas, por lo que sus bases cam- 
biarán según lo hagan las normas y los valores sociales (Ramos e Silva \& Periáñez Cañadillas, 2003).

Desde el enfoque académico, la RSE se ha convertido en una estrategia de gran interés. En este sentido, el profesor de Harvard Business School James Austin afirmaba en 2005 a la revista Dinero que los consumidores valoran positivamente a las empresas involucradas en la sociedad (Vargas, 2006). Además, Austin indicaba que, al decidir sobre dos productos con el mismo precio y calidad, los consumidores escogerán aquellos que estén comprometidos con alguna ONG o tengan buena reputación en el ámbito social. En consecuencia, a partir de los años 90 van a surgir conceptos como marketing con causa social o marketing social corporativo (Ramos e Silva \& Periáńez Cañadillas, 2003). Ambos velarán por aspectos como la imagen de la empresa y su reputación; beneficiándose, a su vez, la relación empresarial, el vínculo con la ciudadanía y con la competencia. Por tanto, que una empresa apoye una causa social coherente con sus políticas puede llevar al consumidor a cambiar de marca y de tienda en apoyo a ese motivo.

\section{MARKETING CON CAUSA SOCIAL Y MARKETING SOCIAL CORPORATIVO}

Con la globalización económica, el marketing se ha convertido en un elemento clave para las alianzas estratégicas y las competencias del comercio internacional (Ramos e Silva \& Periáñez Cañadillas, 2003). Esto se debe a que el marketing permite que una empresa se beneficie de cuidar y planificar sus relaciones de intercambio (Kotler \& Zaltman, 1971).

Se entiende como marketing social corporativo (MSC) a una técnica de marketing que pretende influenciar a un público objetivo para que acepte, modifique o rechace un determinado comportamiento de forma voluntaria en beneficio de la sociedad (Justiniano Moreno, 2020).

El marketing con causa social (MCS) en cambio es una técnica que tiene como finalidad maximizar el beneficio empresarial, mientras apoya las causas benéficas mejores valoradas por los clientes (Recio Méndez, 2004).

Se debe tener en cuenta que el objetivo de ambas herramientas es generar dinero para la empresa. Sin embargo, la principal diferencia entre estas se debe al área de inversión. En el MSC se invierte en actividades filantrópicas, ya sea mediante la venta de productos de fabricación responsable o incentivando a través de campańas un hábito positivo en los consumidores (Justiniano Moreno, 2020). En cambio, en el MCS el dinero se dedica a actividades de publicidad, promoción y relaciones públicas. Por tanto, lo que propone el marketing con causa es destinar un porcentaje de los beneficios de producción a una o varias ONG (García et al., 2001).

La responsabilidad social empresarial hace uso de estas dos estrategias simultáneamente, pues las marcas son conscientes de los beneficios que esto les otorga. En adelante, para que la participación social de las empresas sea aceptada por los consumidores, las marcas deberán ser coherentes en todo momento con sus valores (Ramos e Silva \& Periáńez Cañadillas, 2003). Sin embargo, en la práctica, esto ha 
pecado de numerosas faltas. En este sentido, la desregulación del mercado, unida a la desinformación y la falta de vigilancia hacia las empresas por parte de los consumidores, han propiciado que numerosas entidades eviten actuar éticamente para no tener desventajas económicas a corto plazo. Como señala José N. Vargas: «... la ética se convierte en un obstáculo que contradice en la práctica el discurso que la misma empresa ha construido sobre la responsabilidad social»(Vargas, 2006, p. 21).

Deben mencionarse, por tanto, los múltiples debates en torno a la responsabilidad social de la empresa Nike. Pese a tener una trayectoria de actuaciones positivas hacia la sociedad y el medio ambiente, la firma ha sido cuestionada en distintas ocasiones debido a los escándalos sobre explotación y precariedad laboral en la que se encuentran sus trabajadores (Epstein et al., 2010). Para evitar estas críticas, la empresa ha tomado medidas legales ante diversos proveedores por el incumplimiento de las normas estipuladas en los países de producción y exportación (Vidal Liy, 2021). Entre las críticas más destacadas se encuentran las sucedidas en China, donde las denuncias laborales de la empresa hacia el país asiático continúan hoy día. Recientemente, las firmas H\&M y Nike han declarado públicamente su rechazo a utilizar prendas de algodón producidas en Xinjiang (Hendrix $\&$ Noland, 2021). Esto se debe a que en la cosecha de ese algodón se emplea mano de obra forzada de miles de uigures y otras minorías étnicas. Por consiguiente, la declaración supuso que los medios estatales chinos pidieran a los consumidores que boicotearan los productos de ambas empresas. Además, para Nike significó la ruptura contractual de personajes públicos vinculados a la firma. A este respecto, las protestas de las multinacionales extranjeras se consideró un insulto en China, hasta el punto de observarse las tiendas de ambas firmas vacías en el centro de Pekín (Vidal Liy, 2021).

En este sentido, Nike ha logrado un modelo de empresa capaz de evolucionar en las estrategias de responsabilidad social. Pues aun con sus faltas, ha tomado acción ante las diversas desigualdades que vinculan la fabricación y exportación de sus productos; además de posicionarse públicamente en contra de determinadas injusticias sociales.

\section{ANALIZANDO EL CASO NIKE PROPUESTAS DE NIKE. INC PARA LA INCLUSIÓN SOCIAL EN EL DEPORTE}

NIKE. Inc cuenta actualmente con las firmas Nike y Converse, las cuales tienen como filosofía que todos puedan acceder al deporte (NIKE. Inc, 2021a). A finales de los años 80, las estrategias publicitarias de las marcas deportivas empezaron a asociarse a imágenes de realización y bienestar individual. Con el objeto de difundir una perspectiva más humanista, basada en el amor por el deporte, Nike logró que sus campañas destacasen. Poco a poco, la firma fue dejando a un lado la imagen idealizada de la superación personal, para abordar la diversidad de formas que tienen las metas: sociales, individuales y mentales (Taboada Campos, 2017). En este sentido traspasó la lógica individualista, hasta entender las relaciones con 
los otros desde lo común (Álvarez, 2016). Evidenciándose, sobre todo en sus eslóganes, donde la promesa de la victoria y la superación individual surge como consecuencia de los logros sociales. Nike confía en el deporte, como una herramienta importante para enseñar a los nińos lecciones como el respeto, el trabajo en equipo y la autoestima.

De esta forma, la firma ha abordado en numerosas campañas temas sociales controvertidos como la inmigración, los derechos LGTBQ y el sexismo (Heffron, 2019). Así como discriminaciones por sexo, edad, etnia, discapacidad y fenómenos como el racismo estructural. Como consecuencia, desde las distintas fases de producción y exportación, pretenden velar por la transparencia, la autenticidad y la responsabilidad, entre otros valores (NIKE. Inc, 2021a). En el Informe de Impacto del 2020 se expone cómo las actuaciones de Nike buscan lograr cambios duraderos. Es por ello por lo que los objetivos de este informe esperan lograrse para el año 2025. Algunas de las propuestas sociales más destacadas serían (Nike. Inc, 2020b):

a. Incrementar en un 35\% la representación empresarial de las minorías raciales y étnicas en las plantillas estadounidenses de NIKE. Inc.

b. Invertir 125 millones de dólares para apoyar a las organizaciones que abordan la desigualdad racial.

c. Invertir 10 millones de dólares en colegios y universidades históricamente negros, así como en instituciones que prestan servicios a los hispanos para aumentar las contrataciones directas y en prácticas.

Las ayudas serán emitidas en formas de subsidios y donaciones por parte de la comunidad Nike, como una estrategia de marketing social corporativo. A diferencias de otras empresas, con menor capacidad financiera o compromiso con los Objetivos de Desarrollo Sostenibles (ODS), la empresa tiene las bases para invertir en responsabilidad social a largo plazo, sin verse limitada por las normas de gastos (Epstein et al., 2010).

\section{EL POSICIONAMIENTO DE NIKE CONTRA EL RACISMO ESTRUCTURAL. UN ESTUDIO DE CASO DE LA RSE}

Nike cuenta con una larga trayectoria en la lucha antirracista en EE. UU. En 2018, la empresa lanzaba el anuncio «Dream Crazy» como celebración del treinta aniversario de su campaña "Just Do It». En el spot publicitario, puede visibilizarse a diversos atletas reconocidos por superar dificultades o discapacidades para poder practicar deportes (NIKE. Inc, 2021d). Sin embargo, en esta campaña las miradas se centraron en Colin Kaepernick. El jugador de fútbol era relevante para la firma por su participación en el movimiento BLM y su activismo afroamericano (Heffron, 2019). Durante los diversos partidos de la Liga Nacional de Fútbol Americano (NFL) Kaepernick se arrodilló como protesta al racismo estructural y la brutalidad policial hacia los afroamericanos; este acto hizo que otros jugadores se unieran a él. 
La actuación tuvo rápidamente una respuesta del expresidente de EE. UU. Donald Trump, quien indicó que los jugadores que eligiesen arrodillarse o sentarse durante el himno nacional deberían ser despedidos. Tras este hecho la NFL decidió multar a los equipos cuyos jugadores lo hicieran (García-Navarro \& Davis, 2018). Kaepernick continuó protestando individualmente hasta que consiguió el respaldo de Nike con el spot publicitario "Dream Crazy». Este hecho estuvo acogido por muchos grupos de interés, mientras que simultáneamente fue reconocido como un acto antipatriótico. Como consecuencia se desencadenaron cientos de mensajes en Twitter con los hashtags \#JustBurnIt y \#BoycottNike acompañados de imágenes donde las zapatillas de la firma estaban siendo quemadas. Frente a este rechazo, la campaña fue un éxito, ya que implicó que Nike siguiera adoptando una postura antirracista y por tanto mantuviera una imagen de responsabilidad. Esto se tradujo en las ventas, las cuales crecieron un 31\% frente al año anterior (Heffron, 2019).

El 29 de mayo de 2020, Nike volvió a pronunciarse contra el racismo en Estados Unidos, pero esta vez su actuación se dio de forma automática tras el asesinato de George Floyd (De la Vega Martínez, 2020). EE. UU. ya contaba con una agitación social y política histórica debido a la discriminación, las matanzas masivas y la incriminación de numerosos afroamericanos. Sin embargo, a partir del asesinato de George Floyd se desataron numerosas marchas con la consigna de «Black Lives Matter", la cual tuvo un apoyo internacional. Aunque esta lucha ya contaba con un largo recorrido, no fue hasta el contexto de la pandemia covid-19 donde se vislumbraron exponencialmente todas aquellas inequidades que experimentan día tras día los afroamericanos, como son las faltas de recursos sanitarios, la situación de pobreza y la falta de derechos (Inofuente Peñaloza et al., 2021).

El día del asesinato, las noticias reflejaban las protestas, que cada vez eran más violentas. Ante esta situación, Nike decidió emitir un nuevo anuncio de conciencia social, pero esta vez abandonó el eslogan que le había acompañado desde los años ochenta «Solo hazlo» para decir "Por una vez, no lo hagas» "No le des la espalda al racismo» (Cohen, 2020). El objetivo de la campaña era doble: por un lado, procurar una toma de conciencia sobre el racismo estructural y por otro alentar a la ciudadanía a que actúe en repulsa ante ese tipo de conductas. El comercial se dirigió a los consumidores de Nike, a los grupos sociales como Black Lives Matter y Colors of Change, así como a los simpatizantes al Partido Demócrata (De la Vega Martínez, 2020). Este posicionamiento, a diferencia del anterior, fue una respuesta rápida. En una entrevista, el director ejecutivo de Nike John Donahoe declaraba su oposición al odio, la desigualdad y el fanatismo. Es por ello por lo que, en un momento de lucha racial, de división política y en una pandemia mundial, las personas buscaban cada vez más voces conocidas en las que poder confiar y esto también incluía a las marcas (Cohen, 2020). El posicionamiento público fue clave, pues activó un recurso muy valioso en este contexto, «el capital social» (Nińo-Benavides \& Cortés, 2018). La empresa logró fomentar la confianza hacia la marca y fortalecer la acción colectiva creando bienes públicos y redes. Ante esta situación, el colectivo Nike-UNITED firmó un programa de inversión denominado «Until We All Win» con diversas ONG. Este plan estipuló una donación de 140 millones de dólares durante los próximos 10 años, con el objetivo de apoyar a las organizacio- 
nes enfocadas en el empoderamiento económico, la educación y la justicia social de los afroamericanos, (NIKE. Inc, 2021e). Como consecuencia, todos estos hechos generaron un gran revuelo mediático para Nike, que duraría aproximadamente un mes (De la Vega Martínez, 2020). El impacto de la campańa de Nike fue tan relevante que implicó que su principal competente, Adidas, retuiteara el post de la firma, incluyendo su anuncio, la etiqueta de la campaña Until We All Win y la frase «Seamos parte del cambio». Además de retuitear, Adidas respondió: «Juntos es cómo avanzamos. Juntos es como hacemos el cambio» (La Vanguardia, 2020). Posteriormente, ambas empresas demostraron su apoyo al movimiento Black Lives Matter en sus redes sociales. Por ello, estudiar el caso de Nike de forma comparativa al de Adidas permite comprender el grado de aceptación de Nike como empresa responsable en las redes sociales virtuales.

\section{METODOLOGÍA}

Para entender cómo los debates sobre la RSE ejercen influencia mediática, los días 18 y 25 de abril de 2021 se descargaron de Twitter las menciones a los perfiles @Nike y @Adidas mediante la plataforma NodeXL Pro. Los datos de la red Nike se extrajeron el 18/4/21, fecha en la que diversas ciudades estadounidenses experimentaron revueltas contra la violencia policial hacia los afroamericanos (Rivas, 2021). En cambio, la información de la red Adidas se recogió el 25/4/2021 durante la sentencia del asesinato de George Floyd (Peirón, 2021). En este contexto, ambas marcas hicieron público su apoyo al movimiento Black Lives Matter. Sin embargo, se dejó una semana de diferencia en la extracción de las Api de Twitter. Esta táctica se utilizó para evitar que los lanzamientos de productos de ambas firmas fueran determinantes en la estructura conversacional.

En este sentido, el Api Stream posibilitó monitorear en tiempo real las reacciones e interacciones de los usuarios ante los eventos sociales señalados. La información registrada se importó a los softwares NodeXL pro y SPSS, donde se generaron las métricas y los sociogramas correspondientes a las redes Nike y Adidas. Los sociogramas forman parte de la Teoría de Grafos, de modo que, en el grafo cada nodo se representa como un vértice, que a su vez está conectado por enlaces, también llamados aristas (Humberstone \& Alvarez, 2019) ${ }^{2}$. Por otra parte, las métricas reflejan las diferencias existentes en los vértices y las aristas que hay en las redes.

${ }^{2}$ Los usuarios o nodos en la red son denominados vértices; en cambio, los mensajes directos o menciones se reconocen como aristas. Las aristas se crean en la medida en que un usuario menciona o responde a otro usuario en la red. De esta forma, una arista conecta a dos vértices. Por ello, el análisis presta atención a las aristas dirigidas, por representar un origen y un destino claro en la dirección del mensaje (Hansen et al., 2010). 


\begin{tabular}{|c|c|}
\hline \multicolumn{2}{|c|}{ CUADRO I. PRINCIPALES PROPIEDADES DEL GRÁFICO } \\
\hline Aristas únicas & Hace referencia a los mensajes o menciones no retuiteados. \\
\hline Aristas con duplicados & $\begin{array}{l}\text { Indican el número de vértices repetidos. Esto permite conocer el grado de } \\
\text { retroalimentación de los mensajes y menciones retuiteados. }\end{array}$ \\
\hline Aristas totales & Recuenta los mensajes y menciones totales que hay en una red. \\
\hline Componentes conectados & $\begin{array}{l}\text { Indica los vértices que están conectados entre sí, pero separados de otros en } \\
\text { el gráfico. }\end{array}$ \\
\hline Distancia geodésica máxima & Es la longitud máxima entre dos nodos tomando el camino más largo. \\
\hline Distancia geodésica media & $\begin{array}{l}\text { Es el promedio de todas las distancias geodésicas. Esto señala qué tan cerca } \\
\text { están los miembros de una comunidad de otros. }\end{array}$ \\
\hline Densidad del gráfico & $\begin{array}{l}\text { Va de } 0 \text { a } 1 \text { e indica cuánto de interconectados están los vértices de la red. El } \\
\text { gráfico más denso, es decir, el valor más próximo a } 1 \text {, incluirá más proporción } \\
\text { de aristas para el mismo número de vértices. }\end{array}$ \\
\hline
\end{tabular}

Fuente: elaboración propia a partir de los datos publicados por Hansen et al., 2010.

\section{RESULTADOS}

A continuación, se recogen algunos de los resultados claves en el estudio de redes estructurales. En primer lugar, las métricas de las redes Nike y Adidas presentadas en las tablas i y II manifiestan algunos rasgos relevantes para la investigación. En este sentido, la red Nike dispone de 2194 usuarios conectados mediante 6202 mensajes directos, mientras que la red Adidas tiene 3474 usuarios enlazados por 6860 mensajes directos. Así mismo, cabe destacar que la red de Nike tiene un solo componente conectado, es decir, todos los usuarios de esta red se caracterizan por dirigirse a un usuario concreto en Twitter. En cambio, la red Adidas cuenta con 863 componentes conectados, por lo que los tuits y las menciones están asignadas a distintos usuarios. De la misma manera, la distancia geodésica máxima y media es menor en la red Nike, esto significa que los usuarios de Nike están más cerca entre sí que los de Adidas. Finalmente, la red Nike cuenta con mayor densidad de mensajes por usuarios que la red Adidas.

En resumen, la red Nike presenta un único componente conectado, donde los usuarios se encuentran separados por una media de 2,5 mensajes. Por el contrario, en la red Adidas hay 863 componentes conectados distanciados en un promedio 4,3 mensajes. Estas características permiten indicar que la estructura conversacional de la red Nike se encuentra más densa y enlazada que la estructura de Adidas. 


\begin{tabular}{ll}
\hline \multicolumn{2}{c}{ TABLA I. DATOS ESTRUCTURALES } \\
DE LA RED NIKE \\
\hline \multicolumn{2}{c}{ MÉTRICA DEL GRÁfICO } \\
\hline Tipo de gráfico & Dirigido \\
\hline Vértices & 2194 \\
\hline Arista únicas & 4127 \\
\hline Aristas con duplicados & 2075 \\
\hline Aristas totales & 6202 \\
\hline Componentes conectados & 1 \\
\hline $\begin{array}{l}\text { Distancia geodésica máxima } \\
\text { (diámetro) }\end{array}$ & 4 \\
\hline Distancia geodésica media & 2,52 \\
\hline Densidad del gráfico & $0,99.10^{-3}$ \\
\hline
\end{tabular}

\begin{tabular}{ll}
\hline \multicolumn{2}{c}{ TABLA II. DATOS ESTRUCTURALES } \\
DE LA RED ADIDAS \\
\hline \multicolumn{1}{c}{ MÉTRICA DEL GRÁfICO } \\
\hline Tipo de gráfico & Dirigido \\
\hline Vértices & 3474 \\
\hline Arista únicas & 5682 \\
\hline Aristas con duplicados & 1178 \\
\hline Aristas totales & 6860 \\
\hline Componentes conectados & 863 \\
\hline $\begin{array}{l}\text { Distancia geodésica máxima } \\
\text { (diámetro) }\end{array}$ & 13 \\
\hline \begin{tabular}{l} 
Distancia geodésica media \\
\hline Densidad del gráfico
\end{tabular} & 4,4 \\
\hline
\end{tabular}

Fuente: elaboración propia a partir de los datos de NodeXL Pro.

\section{DIFERENCIAS ESTRUCTURALES DE LAS REDES}

En las figuras 1 y 2 se observa cómo aparentemente las redes Nike y Adidas tienen estructuras conversacionales distintas. No obstante, se realizó una prueba $t$ de Student para comprobar si las diferencias entre ambas son estadísticamente significativas. Para ello, en las variables de agrupación se situaron las empresas Nike y Adidas, mientras que en las variables para contrastar están las métricas grado de entrada, grado de salida, centralidad de interrelación, centralidad de proximidad, centralidad de vectores propios y el coeficiente de agrupación (Hansen et al., 2010). Las dos primeras permiten conocer cuántos mensajes directos están conectados a cada usuario. De manera que:

- El grado de entrada (In Degree) mide el número de mensajes que se dirigen hacia un usuario.

- El grado de salida (Out Degree) calcula el número de mensajes que salen de cada usuario.

Las cuatro siguientes abordan las propiedades de cercanía y centralidad de los usuarios en la red:

- La centralidad de interrelación (Betweenness Centrality) permite conocer el grado de mediación entre los vértices. Cuanto más se aproximen a cero, más conectados estarán todos los usuarios de la red. 


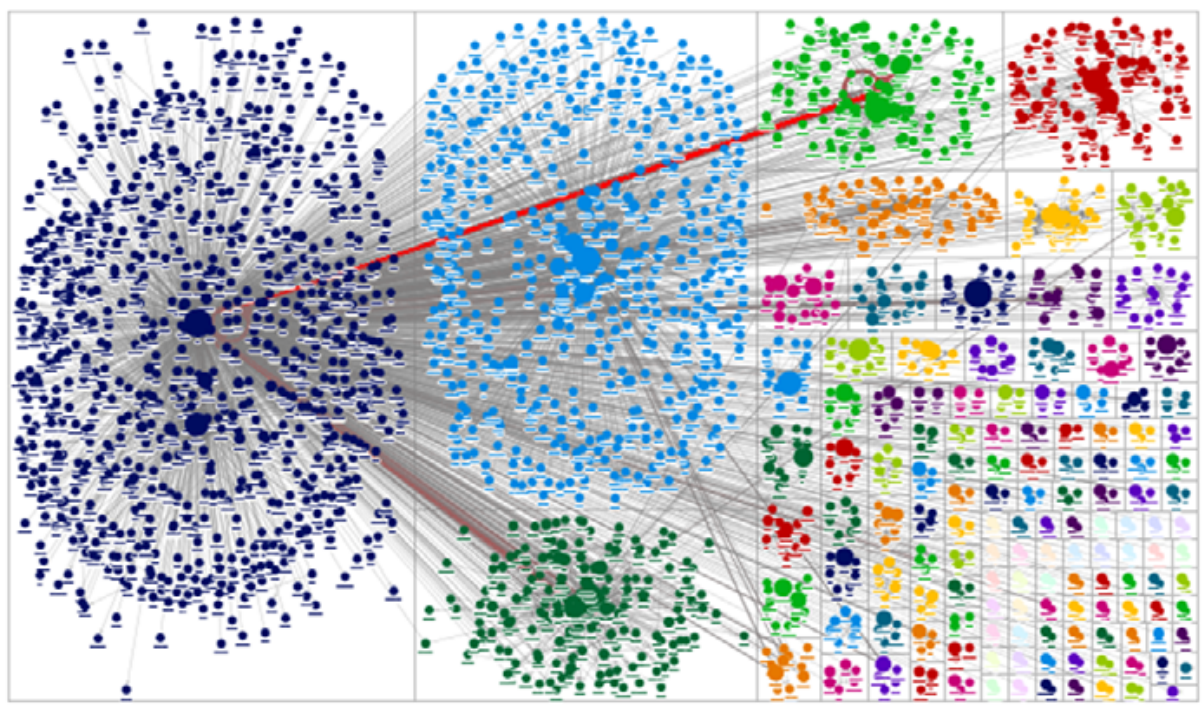

Figura 1. Menciones al perfil @Nike.

Fuente: elaboración propia a partir de los datos de NodeXL Pro.

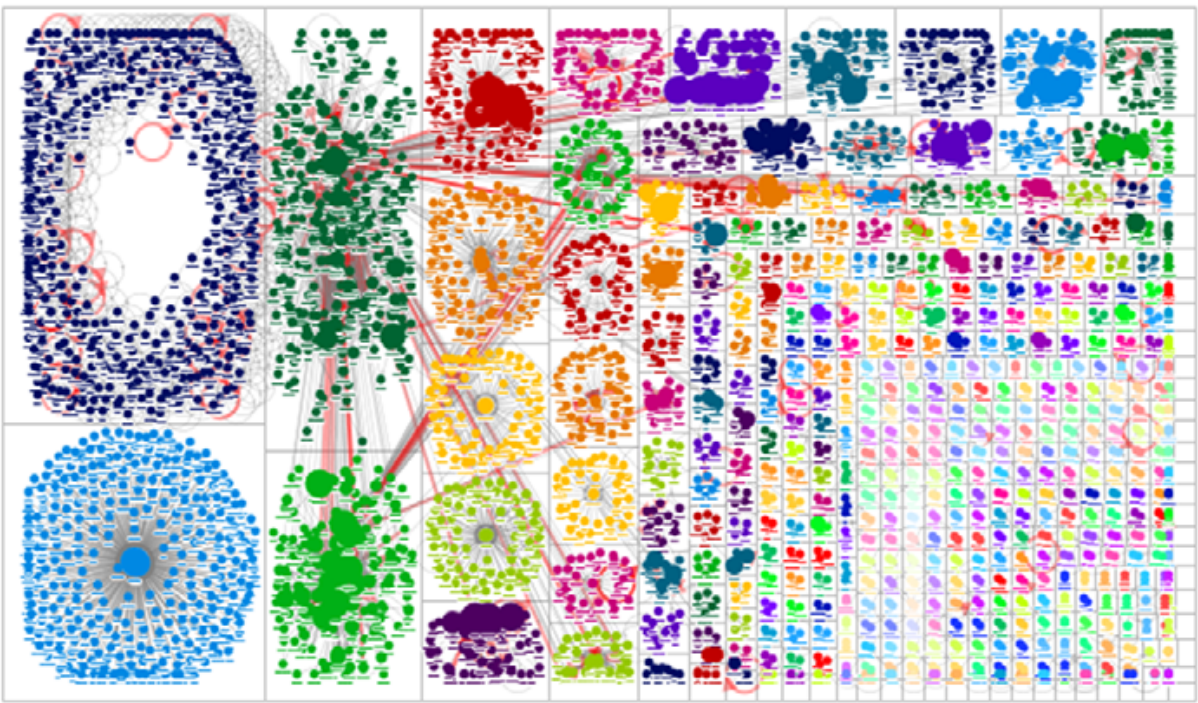

Figura 2. Menciones al perfil @Adidas.

Fuente: elaboración propia a partir de los datos de NodeXL Pro. 
- La centralidad de proximidad (Closeness Centrality) indica cómo de cerca está cada usuario de los otros en la red. Cuanto más se aproxime este valor a cero, más afines estarán los vértices y por tanto más céntrica será la red.

- La centralidad de vectores propios (Eigenvector Centrality) mide cuántas conexiones tiene cada usuario y también el grado en que esos vértices están conectados entre sí.

- El coeficiente de agrupación (Clustering Coefficient) analiza el número de conexiones que unen a un usuario con los usuarios vecinos. Cuanto mayor sea la conexión, mejor fluirá la información en la red.

Los resultados obtenidos en la tabla iII permiten exponer que las variables Nike y Adidas presentan diferencias estadísticas significativas en las métricas grado de salida, centralidad de proximidad, centralidad de vectores propios y en el coeficiente de agrupación, donde Sig. (bilateral) es 0,000<0,05. En cambio, no se generan diferencias estadísticas en el grado de entrada ni en la centralidad de interrelación, donde ambas cuentan con una significación $>0,05$. Para poder visualizarlo se ha realizado un gráfico de barras de error simple para cada una de las variables.

Así mismo, en los gráficos se destacan algunas características relevantes. En primer lugar, en la figura 3a) se expone una diferencia significativa en el grado de salida para ambas empresas. En este sentido, la media de mensajes que salen de los usuarios es estadísticamente superior en la red Nike. Esto se puede visualizar en la figura 4, donde los distintos usuarios de la red conversacional Nike tuitean y mencionan exclusivamente al usuario @Nike. En cambio, en la figura 5 se aprecia cómo una pequeña proporción de los usuarios de la red Adidas se dirigen al usuario@ Adidas en sus mensajes.

Por otra parte, en la figura 3b) la centralidad de proximidad es estadísticamente inferior en la red Nike, donde el valor se aproxima a cero. Esto significa que los usuarios de Nike están más cerca entre sí, de modo que su red es más central que la red Adidas. Además, en las figuras 3c) y 3d) se aprecia que la red Nike también cuenta con una diferencia significativa en la centralidad de vectores y en el coeficiente de agrupación con respecto a Adidas. Al ser mayor el promedio de Nike se puede indicar que los usuarios de esta red están más interconectados, por lo que sus mensajes fluirán rápidamente.

Pese a no haber diferencias significativas entre las medias del grado de entrada ni tampoco en la centralidad de interrelación, sí que existen variaciones relevantes para el estudio. En este sentido, la media de Nike también es mayor en ambas variables, de modo que en la red Nike hay más enlaces dirigidos hacia los usuarios que en la red Adidas. Así mismo, todos los vértices de la red Nike están más conectados entre sí, que la red Adidas.

En resumen, si existen diferencias significativas en las variables grado de salida, centralidad de proximidad, centralidad de vectores propios y coeficiente de agrupación a excepción del grado de entrada y la centralidad de interrelación. Una vez analizadas estas variables se expone que los vértices de la red Nike se encuentran más cercanos los unos de los otros, dando lugar a una red con propiedades de centralidad donde la información fluye de forma rápida y directa hacia el usuario 


\begin{tabular}{|c|c|c|c|c|c|c|c|c|c|c|}
\hline & & TABLA & III. DIS & STRIB & CIÓN T & DE ST & UDENT PA & RA NIKE Y & ADIDAS & \\
\hline & & & & Prui & BA DE MUE & ESTRAS I & 'NDEPENDIEN' & TES & & \\
\hline & & $\begin{array}{r}\text { Pruei } \\
\text { DE LeV } \\
\text { DE IGUAI } \\
\text { DE VARIA }\end{array}$ & $\begin{array}{l}\text { BA } \\
\text { ENE } \\
\text { LDAD } \\
\text { NZAS }\end{array}$ & & & Pruef & BA T PARA LA I & GUALDAD DE & MEDIAS & \\
\hline & & $\mathrm{F}$ & Sig. & $\mathrm{t}$ & $\mathrm{gl}$ & $\begin{array}{l}\text { Sig. } \\
\text { (bilate- }\end{array}$ & DIFERENCIA & $\begin{array}{l}\text { DIFERENCIA } \\
\text { DE ERROR }\end{array}$ & $\begin{array}{r}95 \% \text { DE INTER } \\
\text { FIANZA DE LA }\end{array}$ & $\begin{array}{l}\text { VALO DE CON- } \\
\text { DIFERENCIA }\end{array}$ \\
\hline & & & & & & & DE MEDIAS & ESTÁNDAR & INFERIOR & SUPERIOR \\
\hline 율 & $\begin{array}{l}\mathrm{Se} \\
\text { asumen } \\
\text { varianzas } \\
\text { iguales }\end{array}$ & 1,279 & 0,258 & 0,579 & 5666 & 0,562 & 0,387266 & 0,668283 & $-0,922824$ & 1,697355 \\
\hline जै & $\begin{array}{l}\text { No se } \\
\text { asumen } \\
\text { varianzas } \\
\text { iguales }\end{array}$ & & & 0,481 & 2484,259 & 0,630 & 0,387266 & 0,804371 & $-1,190041$ & 1,964572 \\
\hline$\frac{\pi}{7} \frac{\pi}{\pi}$ & $\begin{array}{l}\text { Se } \\
\text { asumen } \\
\text { varianzas } \\
\text { iguales }\end{array}$ & 2,008 & 0,157 & 5,525 & 5666 & 0,000 & 0,387266 & 0.070088 & 0,249866 & 0,524665 \\
\hline जि: & $\begin{array}{l}\text { No se } \\
\text { asumen } \\
\text { varianzas } \\
\text { iguales }\end{array}$ & & & 5,592 & 4844,583 & 0,000 & 0,387266 & 0,069259 & 0,251487 & 0,523044 \\
\hline $\begin{array}{l}\frac{\pi}{0} \\
\frac{\pi}{0}: \frac{0}{0} \\
\frac{0}{0}\end{array}$ & $\begin{array}{l}\text { Se } \\
\text { asumen } \\
\text { varianzas } \\
\text { iguales }\end{array}$ & 4,250 & 0,039 & 1,269 & 5666 & 0,204 & 2171,739940 & 1711,195898 & $-1182,858994$ & 5526,338875 \\
\hline 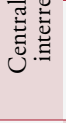 & $\begin{array}{l}\text { No se } \\
\text { asumen } \\
\text { varianzas } \\
\text { iguales }\end{array}$ & & & 1,024 & 2284,303 & 0,306 & 2171,739940 & 2121,122725 & $-1987,788162$ & 6331,268042 \\
\hline 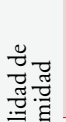 & $\begin{array}{l}\text { Se } \\
\text { asumen } \\
\text { varianzas } \\
\text { iguales }\end{array}$ & 3032,187 & 0,000 & $-25,125$ & 5666 & 0,000 & $-0,188143$ & 0,007488 & $-0,202823$ & $-0,173463$ \\
\hline 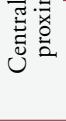 & $\begin{array}{l}\text { No se } \\
\text { asumen } \\
\text { varianzas } \\
\text { iguales }\end{array}$ & & & $-31,617$ & 3473,000 & 0,000 & $-0,188143$ & 0,005951 & $-0,199811$ & $-0,176476$ \\
\hline 莺 & $\begin{array}{l}\mathrm{Se} \\
\text { asumen } \\
\text { varianzas } \\
\text { iguales }\end{array}$ & 17,943 & 0,000 & 14,295 & 5666 & 0,000 & 0,000459 & 0,000032 & 0,000396 & 0,000522 \\
\hline 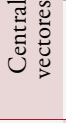 & $\begin{array}{l}\text { No se } \\
\text { asumen } \\
\text { varianzas } \\
\text { iguales }\end{array}$ & & & 16,569 & 5262,960 & 0,000 & 0,000459 & 0,000028 & 0,000405 & 0,000514 \\
\hline 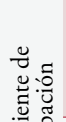 & $\begin{array}{l}\text { Se } \\
\text { asumen } \\
\text { varianzas } \\
\text { iguales }\end{array}$ & 49,265 & 0,000 & 20,593 & 5666 & 0,000 & 0,142632 & 0,006929 & 0,129055 & 0,156210 \\
\hline ن & $\begin{array}{l}\text { No se } \\
\text { asumen } \\
\text { varianzas } \\
\text { iguales }\end{array}$ & & & 20,570 & 4645,835 & 0,000 & 0,142632 & 0,006934 & 0,129039 & 0,156226 \\
\hline
\end{tabular}

Fuente: elaboración propia a partir de los datos de NodeXL Pro. 
a)

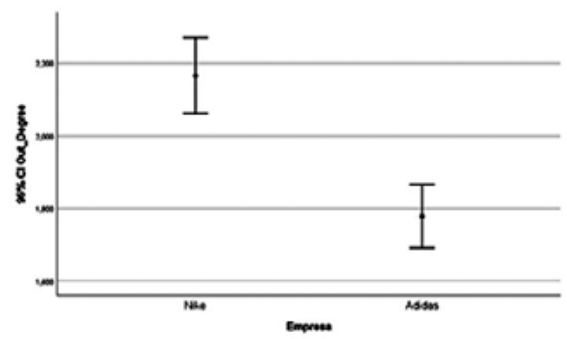

c)

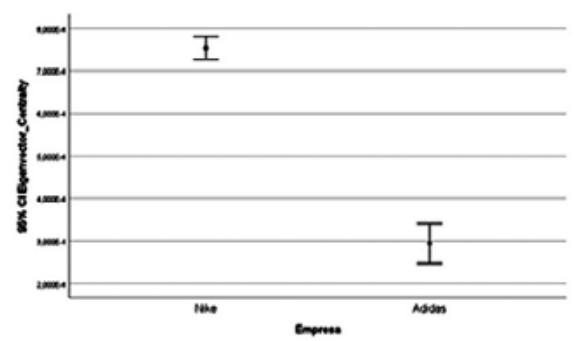

e)

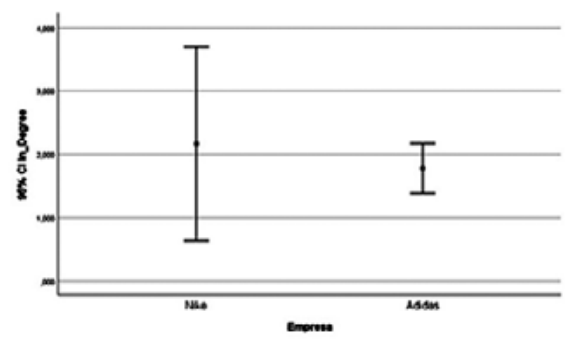

b)

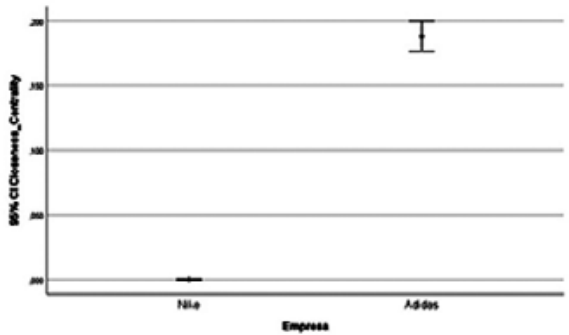

d)

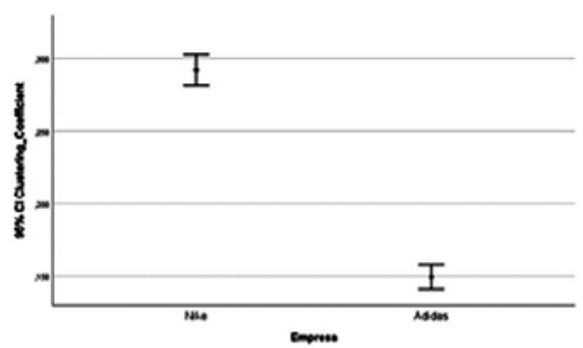

f)

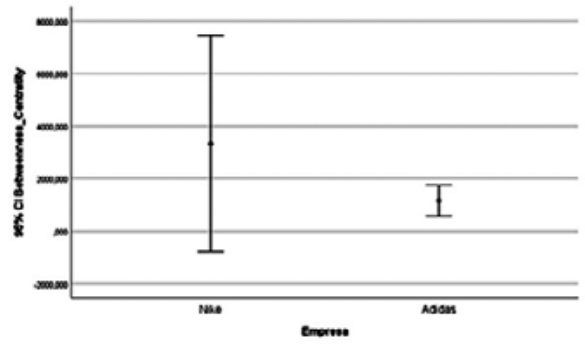

Figura 3. Diferencias estructurales para cada una de las variables. a) Grado de salida.

b) Centralidad de proximidad. c) Centralidad de vectores propios. d) Coeficiente de agrupación.

e) Grado de entrada. f) Centralidad de interrelación.

Fuente: elaboración propia a partir de los datos de NodeXL Pro.

$@$ Nike. Mientras que en la red Adidas ocurre todo lo contrario. Se puede por tanto aceptar la Hipótesis 1 e indicar que las redes de Nike y Adidas tienen estructuras conversacionales distintas. 


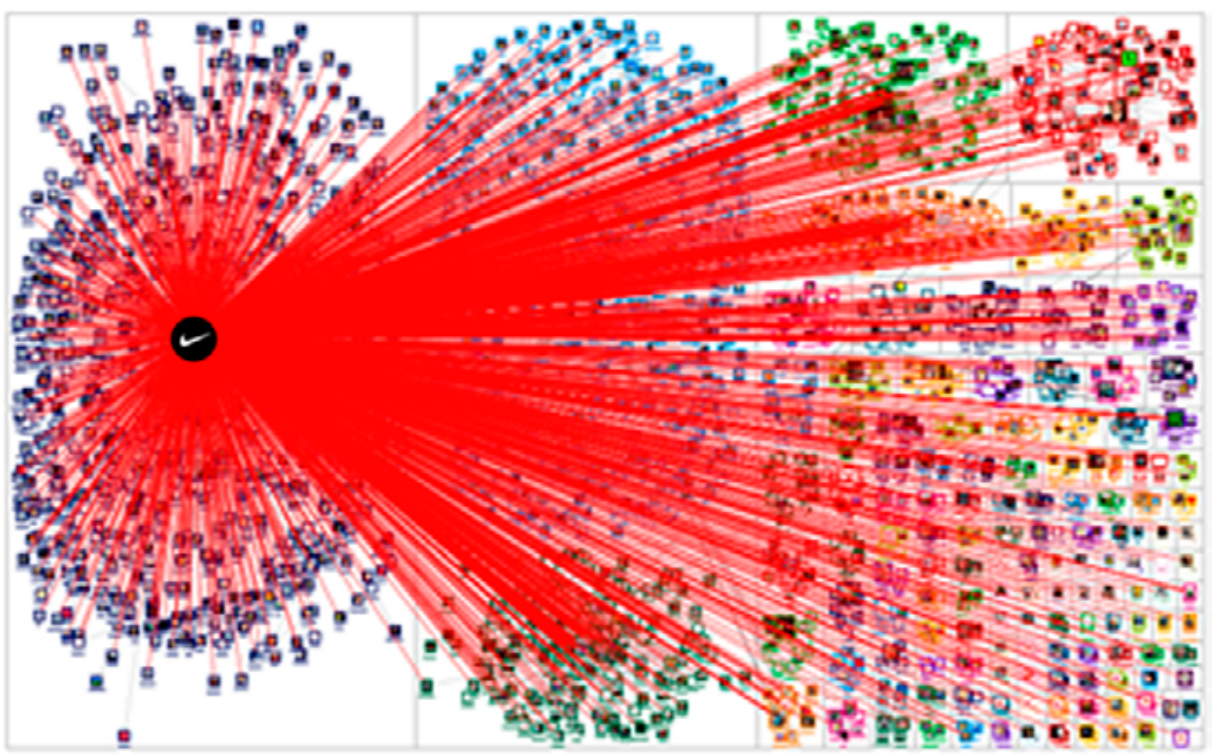

Figura 4. Grado de salida del usuario @Nike.

Fuente: elaboración propia a partir de los datos de NodeXL Pro.

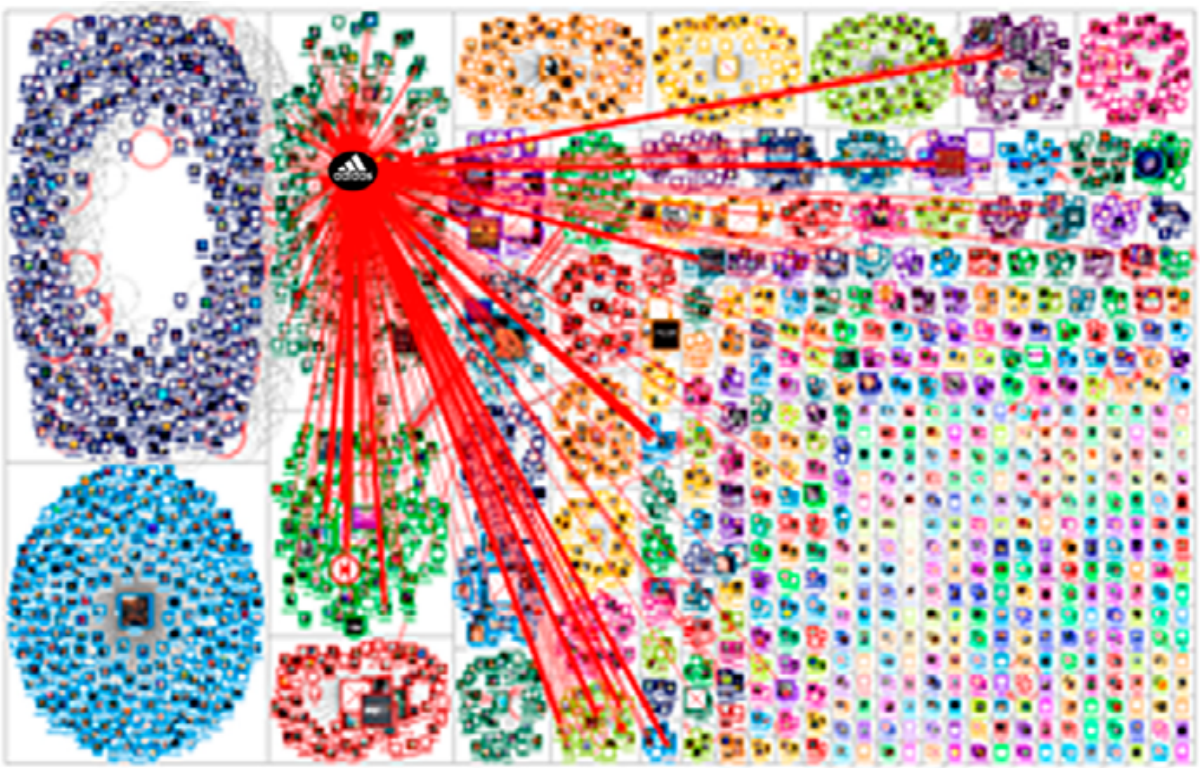

Figura 5. Grado de salida del usuario @Adidas.

Fuente: elaboración propia a partir de los datos de NodeXL Pro. 


\section{DIFERENCIAS CONVERSACIONALES EN LAS REDES}

Para conocer en qué medida varían los mensajes de cada red se seleccionó en la base de datos la información de los seis primeros grupos conversacionales ${ }^{3}$. Estos se caracterizaron por obtener en la métrica de grupo más de treinta vértices. Seguidamente, se filtraron los datos de los grupos extrayendo los grados de entrada y de salida de cada grupo en una hoja de cálculo. En tercer lugar, se codificaron los datos en función de la empresa y el grupo al que pertenecen. Finalmente, se realizó una prueba t de Student y un gráfico de barras de error simple para ambas variables.

Los resultados obtenidos indican que en el grupo 5 de la figura 6 , la media de los mensajes que se dirigen a Nike es estadísticamente superior a la de la red Adidas. Al analizar el contenido conversacional de este grupo se observó que predominan los mensajes sobre la actuación de la empresa. Estos tuits vinculan a Nike con diversos sucesos y colectivos de personas, como puede observarse en el cuadro II. Mientras, en el cuadro III se aprecia que en la red Adidas, todos los mensajes de este grupo giran en torno al comercial de su último lanzamiento.

Indagando en los datos, no se encuentran más diferencias significativas entre las medias, sin embargo, se destacan las halladas en el grupo 1, donde el promedio del grado de entrada en Nike es muy superior al de Adidas. En este grupo, los mensajes de la red Nike se concentran en torno a un tuit emitido por la propia empresa, como se indica en la figura 4. Este mensaje reflejado en el cuadro II abordaba el reconocimiento de las mujeres negras en el ámbito laboral. En cambio, las conversaciones de este grupo en Adidas son muy diversas abarcando desde características de sus productos hasta datos sobre la empresa y comparaciones con otras firmas.

Por otra parte, la figura 7 presenta diferencias estadísticamente significativas en el grado de salida para los grupos $1,2,4$ y 6 . Siendo la media superior para la red Nike en los grupos 1, 2 y 6 y para la red Adidas en el grupo 4.

En el grupo 1, los mensajes de las redes Nike y Adidas abordan las mismas temáticas tratadas con anterioridad en el grado de entrada.

En cambio, el grupo 2 de la red de Nike se ha formado a partir de un mensaje emitido por la reportera de Fox News Laura Ingraham. En él indicaba su descontento hacia el saqueo que algunos miembros de Antifa realizaron en una de las tiendas de Nike durante las revueltas contra el racismo en EE. UU. (Rivas, 2021). Es por ello por lo que en el grado de salida se encuentra este mensaje y otros de usuarios en respuestas a Nike y Laura Ingraham. Como se puede observar en el cuadro II, los debates se centran en el repudio hacia Nike por su involucración con el movimiento Black Lives Matter y la vinculación de este con el grupo Antifa. Por otro lado, en la red Adidas, todos los mensajes del grupo 2 van vinculados a un sorteo emitido por uno de los usuarios de Twitter sobre las «Sneakers ciberpunk», como se expone en el

${ }^{3}$ NodeXL Pro clasifica los grupos conversacionales mediante algoritmos de agrupamiento. Las aristas (mensajes) se agrupan según el nivel de acuerdo. Además, la plataforma permite detectar las palabras más utilizadas por las personas en ese grupo (Hansen et al., 2010). 


\begin{tabular}{|c|c|c|}
\hline \multicolumn{3}{|c|}{ CUADRO II. CONVERSACIONES AGRUPADAS DE LA RED NIKE } \\
\hline Grupos & CONVERSACIONES AGRUPADAS & Mensajes \\
\hline \multirow{3}{*}{1} & \multirow{3}{*}{$\begin{array}{l}\text { Nike despertó saqueada; } \\
\text { simpatía marxista; } \\
\text { reparaciones de consumo. }\end{array}$} & $\begin{array}{l}\text { A las mujeres negras rara vez se les reconoce el duro trabajo que } \\
\text { realizan. No es sólo magia, son la realidad. Únete a nosotros para } \\
\text { celebrar su duro trabajo y ayudar a nivelar el campo de juego } \\
\text { \#WePlayReal. }\end{array}$ \\
\hline & & $\begin{array}{l}\text { Sin embargo, @Nike seguirá apoyando la basura marxista que se } \\
\text { refiere a saqueo como «reparación» al consumidor [...]. No simpatía. }\end{array}$ \\
\hline & & Saqueadores criminales. Las vidas Importan. \\
\hline \multirow{3}{*}{2} & \multirow{3}{*}{$\begin{array}{l}\text { Tienda Nike en Portland; } \\
\text { donando millones; } \\
\text { intento de saqueo. }\end{array}$} & Me pregunto si el equipo tiene algo que decir al respecto. \\
\hline & & $\begin{array}{l}\text { Portland: \#Antifa destrozó la tienda Nike en el centro de la ciudad } \\
\text { en su disturbio. Intentaron saquearlo el Año pasado, pero el equipo } \\
\text { de seguridad de la tienda los detuvo. @Nike se ha comprometido a } \\
\text { donar decenas de millones a \#BLM. \#PortlandRiots. }\end{array}$ \\
\hline & & $\begin{array}{l}\text { De hecho apoyo el vandalismo en todas las tiendas de Nike. Estoy } \\
\text { bastante seguro de que todos los conservadores pueden respaldar } \\
\text { esto [...]. }\end{array}$ \\
\hline \multirow{3}{*}{3} & \multirow{3}{*}{$\begin{array}{l}\text { Tienda Nike; auténticos } \\
\text { almirantes de las zapatillas } \\
\text { Britt Baker; gracias. }\end{array}$} & $\begin{array}{l}\text { Maldita sea, mucha gente que conozco los tiene de la misma } \\
\text { manera excepto yo. }\end{array}$ \\
\hline & & $\begin{array}{l}\text {... Llevas la división femenina en tu espalda. Lo mínimo que podrías } \\
\text { hacer (@Usuario) es comprarte un par de zapatos cómodos para } \\
\text { usar mientras lo haces. }\end{array}$ \\
\hline & & No puedo obtener nada. (Dirección web). \\
\hline \multirow{3}{*}{4} & \multirow{3}{*}{$\begin{array}{l}\text { \#sneakerscouts ahora } \\
\text { disponible. }\end{array}$} & $\begin{array}{l}\text { Me tomó un par de entradas para calentarme con estos, pero son } \\
\text { tan diferentes que estoy aprendiendo a amarlos. }\end{array}$ \\
\hline & & $\begin{array}{l}\text {... Por favor @Nike, no subas los uniformes de la edición de la ciudad } \\
\text { de (@Usuario) Como si hubieran estropeado todos los uniformes } \\
\text { de la @NBA y los uniformes de RedSox. Gracias. }\end{array}$ \\
\hline & & (Dirección web). \\
\hline \multirow{3}{*}{5} & \multirow{3}{*}{$\begin{array}{l}\text { Nike; Adidas; H \& M; } \\
\text { China; cancelación cultural. }\end{array}$} & $\begin{array}{l}\text {... cancelar la cultura sobre las filas de Xinjiang junto con las or- } \\
\text { ganizaciones occidentales de izquierda \#China \#Antifa \# Xinjiang } \\
@ \text { HM @Nike [...]. }\end{array}$ \\
\hline & & Para ayudar a los hermanos y hermanas musulmanes [...] @Nike. \\
\hline & & El desafío de China a @Nike y @Adidas. (Dirección web). \\
\hline \multirow{3}{*}{6} & \multirow{3}{*}{ Nike; campeón de apoyo. } & $\begin{array}{l}\text { (@Usuarios) ¡Me alegra que los ames! Apreciemos el apoyo al } \\
\text { campeón. }\end{array}$ \\
\hline & & $\begin{array}{l}\text { (@Usuarios) ¡Muchas gracias por responder! ¡Me encantan los } \\
\text { zapatos! }\end{array}$ \\
\hline & & (@Usuarios) El mejor atleta que jamás haya existido. \\
\hline
\end{tabular}

Fuente: elaboración propia a partir de los datos de NodeXL Pro.

cuadro III. Por tanto, el grado de salida del grupo 2 en Adidas está conformado por las menciones de diversos usuarios hacia el que organiza el sorteo.

A diferencia de las anteriores, en el grupo 4 se observa cómo el grado de salida de Nike es inferior estadísticamente al de Adidas. En la red Nike, las conver- 


\section{CUADRO III. CONVERSACIONES AGRUPADAS DE LA RED ADIDAS}

\begin{tabular}{|c|c|c|}
\hline Grupos & Conversaciones aGrupadas & Mensajes \\
\hline \multirow{3}{*}{1} & \multirow{3}{*}{ Adidas; Nike; zapatos. } & Adidas y Nike (enlace). \\
\hline & & $\begin{array}{l}\text { Snipes y Adidas celebran el Detroit Pistons con la nueva colabo- } \\
\text { ración (enlace). }\end{array}$ \\
\hline & & $\begin{array}{l}\text { Beyoncé es una de las } 20 \text { celebridades y figuras del deporte que } \\
\text { aparecen en la nueva campaña de la marca Adidas titulada Impo- } \\
\text { sible es nada (enlace). }\end{array}$ \\
\hline 2 & Adidas; sorteo. & $\begin{array}{l}\text {... Quien quiere un par de estos limitados \#Cyberpunk2077 por } \\
\text { zapatillas Adidas (¡solo existen Asia!) solo sigue a (@Usuario) y } \\
\text { comenta aquí el tamaño deseado*. }\end{array}$ \\
\hline \multirow{3}{*}{3} & \multirow{3}{*}{$\begin{array}{l}\text { Adidas; Team Viewer; } \\
\text { \#glazersout. }\end{array}$} & $\begin{array}{l}\text { (@Usuarios) Todo el mundo está tratando de sacar a los Glazer } \\
{[\ldots . . \text {. Realmente no me gusta (@Usuario) pero está haciendo lo que }} \\
\text { cree correcto [...]. }\end{array}$ \\
\hline & & $\begin{array}{l}\text {... Parece como un gran problema no incluir patrocinadores en } \\
\text { esas decisiones [...]. }\end{array}$ \\
\hline & & (@Usuarios) Tiene algo de vergüenza \#Glazersout [...]. \\
\hline \multirow{3}{*}{4} & \multirow{3}{*}{$\begin{array}{l}\text { Adidas; } \\
\text { auspicien deportistas. }\end{array}$} & $\begin{array}{l}\text {... Adidas mejor auspicien a deportistas, no influencers sin criterio } \\
{[\ldots] \text {. }}\end{array}$ \\
\hline & & $\begin{array}{l}\text {... Pero que belleza de embajadora. Antes apoyaban a deportistas } \\
{[\ldots] »}\end{array}$ \\
\hline & & $\begin{array}{l}\text {... Nos urge conocer los nuevos proyectos de (@Usuario), mientras } \\
\text { tanto, nos lo encontramos muy misterioso con un outfit cool y } \\
\text { relajado. Tenis Stan Smith (@Usuarios) (enlace). }\end{array}$ \\
\hline \multirow[b]{2}{*}{5} & \multirow{2}{*}{$\begin{array}{l}\text { Adidas; comercial; } \\
\text { Adidas Original. }\end{array}$} & Estoy en un comercial de Adidas (enlace). \\
\hline & & $\begin{array}{l}\text { Lanzamos el foro ultra exclusivo@Adidas original x@Snipes_usa } \\
{[\ldots . . .]}\end{array}$ \\
\hline \multirow[t]{2}{*}{6} & \multirow{2}{*}{$\begin{array}{l}\text { Adidas Original por DPR; } \\
\text { disponible online. }\end{array}$} & $\begin{array}{l}\text { Por separado pero sincronizado. Adidas Original X DPR [...]. } \\
\text { Disponible en línea [...]. }\end{array}$ \\
\hline & & Adidas Original X DPR en línea (enlace). \\
\hline
\end{tabular}

* Único mensaje textual vinculado al grupo 2 en la red Adidas.

Fuente: elaboración propia a partir de los datos de NodeXL Pro.

saciones abarcan las temáticas productos y comerciales. Estos se dirigen a su vez a las distintas cuentas de NIKE.Inc en Twitter. En cambio, en el grupo 4 de la red Adidas, los mensajes son críticas hacia los influenciadores y embajadores de la firma. Por tanto, todos estos enlaces se dirigen de forma directa al usuario @Adidas.

Finalmente, el grado de salida del grupo 6 de Nike vuelve a ser superior al de Adidas. En el cuadro II se evidencia cómo los mensajes de este grupo en la red Nike están vinculados a deportistas. En cambio, en la red Adidas todos los mensajes son retuits de la información sobre el punto de venta online de unas zapatillas de la firma.

En resumen, los datos demuestran algunas diferencias estadísticas significativas en los grupos conversacionales. Además, se observó que los mensajes de la red Nike apelan de forma notoria a la responsabilidad social con los distintos 


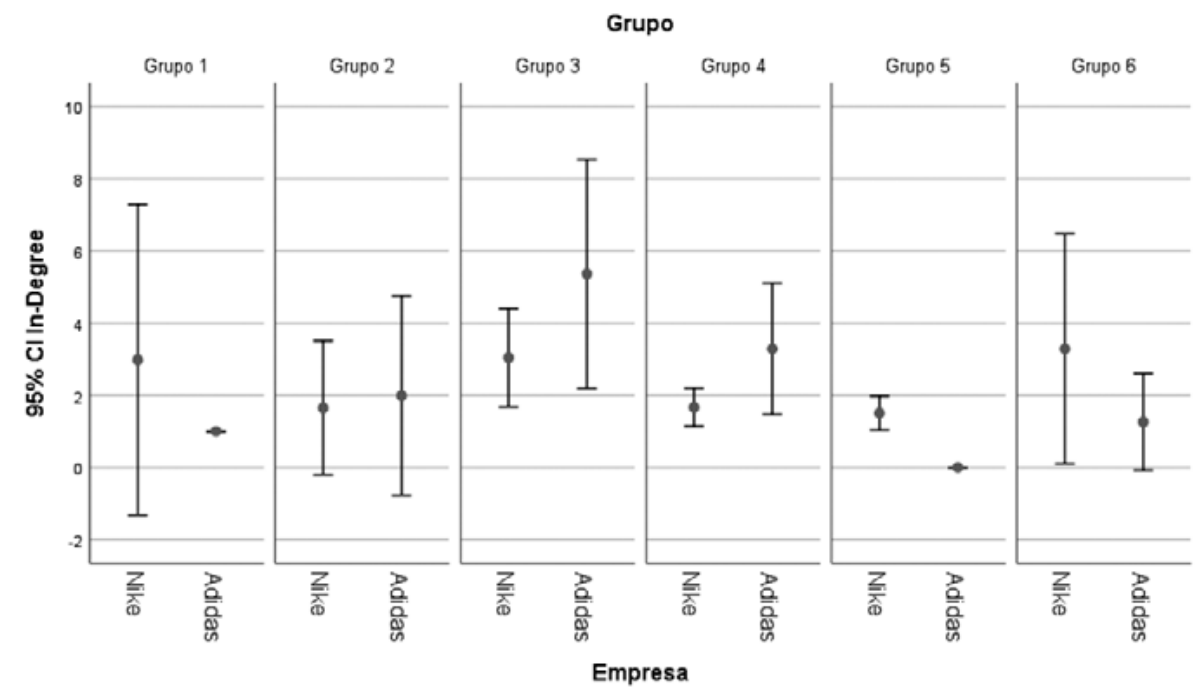

Figura 6. Grado de entrada de las redes Nike y Adidas en función del grupo conversacional. Fuente: elaboración propia a partir de los datos de NodeXL Pro.

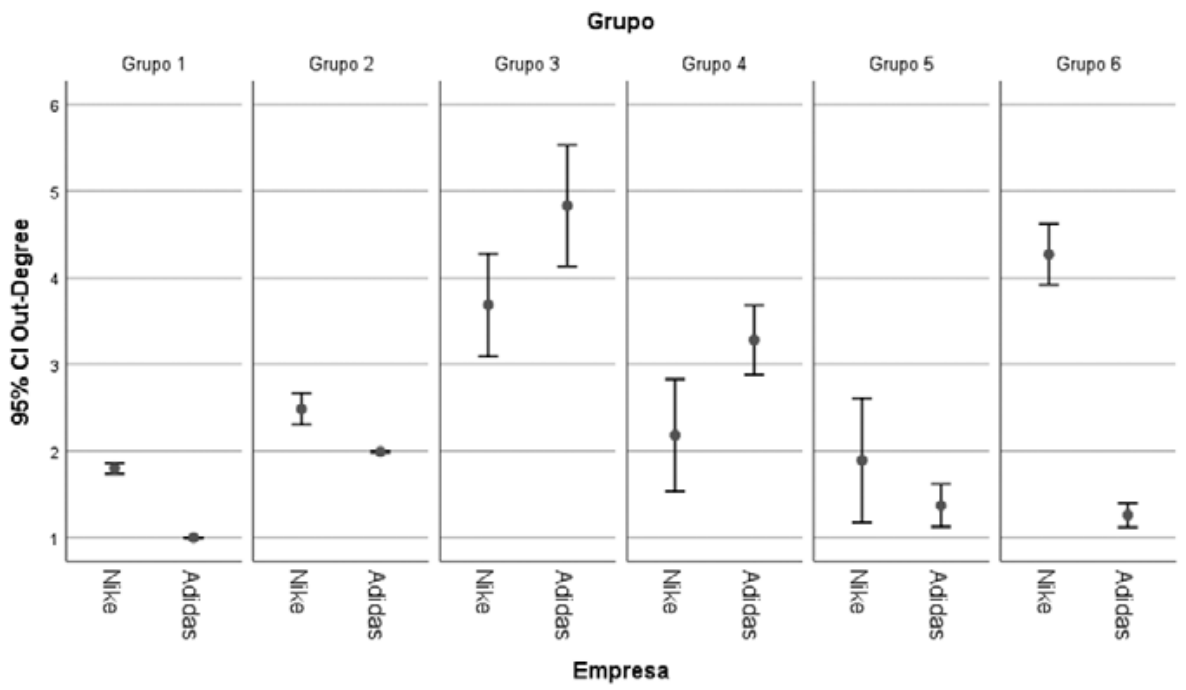

Figura 7. Grado de salida de las redes Nike y Adidas en función del grupo conversacional. Fuente: elaboración propia a partir de los datos de NodeXL Pro. 
colectivos, especialmente se aborda su vinculación con el movimiento Black Lives Matter. Mientras que en la red Adidas predominan los mensajes sobre los productos y campañas publicitarias. No obstante, pese a hallarse evidencias, los resultados obtenidos no permiten indicar que las comunidades internas de la red Nike estén categorizadas únicamente por mensajes sobre la responsabilidad social de la marca.

Por tanto, los resultados obtenidos no permiten aceptar la Hipótesis 2. Esto se debe fundamentalmente a que no existen diferencias estadísticas significativas para la mayoría de los grupos conversacionales en el grado de entrada. Sin embargo, los datos expuestos llevan a plantear dos estrategias metodológicas para corroborar este planteamiento. Es por ello por lo que ampliar la cantidad de datos o realizar un estudio longitudinal del mismo con distintas extracciones quizás sea en un futuro, el desenlace para este estudio.

\section{INFLUENCIAS POLÍTICAS EN LAS REDES CONVERSACIONALES}

Anteriormente se observaron diferencias estructurales y conversacionales en las redes. Por tanto, en este apartado se abordará si las estructuras también pueden diferir según la carga política de las respuestas. Para responder a esto se analizaron los datos partiendo del barómetro político estadounidense del periódico El País (Abad Liñán \& Clemente, 2020).

En el tratamiento de datos se depuró y codificó la geolocalización de los vértices en demócratas (1), republicanos (2) y valores perdidos (-1). Seguidamente se importaron los datos del grado de entrada y de salida a SPSS aplicando una selección de casos por empresa (seleccionar casos si empresa $=1$ o 2) siendo la empresa 1 Nike y la 2 Adidas. Nuevamente se realizó una prueba t de Student, pero esta vez, las variables de agrupación eran los estados demócratas y republicanos, mientras que en las variables para contrastar se encuentran el grado de entrada y el grado de salida. Los resultados obtenidos fueron los siguientes:

En primer lugar, no se manifiestan diferencias estadísticamente significativas entre las variables de la red Nike, pese a ello, la información encontrada es relevante. Por ejemplo, en la figura 8 se observa que la media del grado de entrada en Nike abarca un rango mayor en los estados demócratas. Por tanto, se propone que una amplia proporción de los mensajes se emitieron a usuarios situados en los estados demócratas. Sin embargo, este enunciado no puede afirmarse. Además, en la figura 9 se observa cómo los mensajes han sido emitidos de forma relativamente similar en los estados demócratas y republicanos, aunque es ligeramente superior en los demócratas.

Por otra parte, en la figura 11 se observa una diferencia estadística significativa en el grado de salida de la red Adidas. Aunque esta sea relativamente pequeña, sí que muestra información sustancial. En este sentido, los datos permiten afirmar que son los usuarios situados en los estados republicanos, los que más mensajes directos, tuits y menciones emiten. Si se relaciona esta información, con la obtenida en el apartado anterior, puede por tanto apuntar que la mayoría de los mensajes de la 


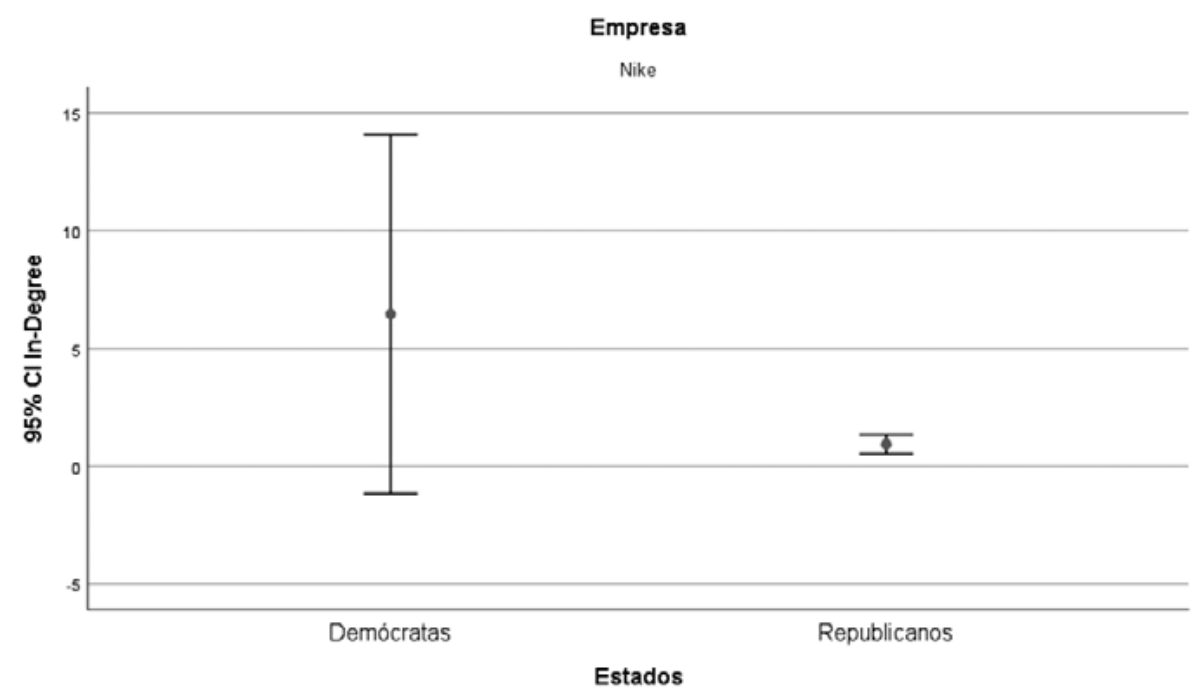

Figura 8. Grado de entrada para la red Nike según la influencia política Fuente: elaboración propia a partir de los datos de NodeXL Pro.

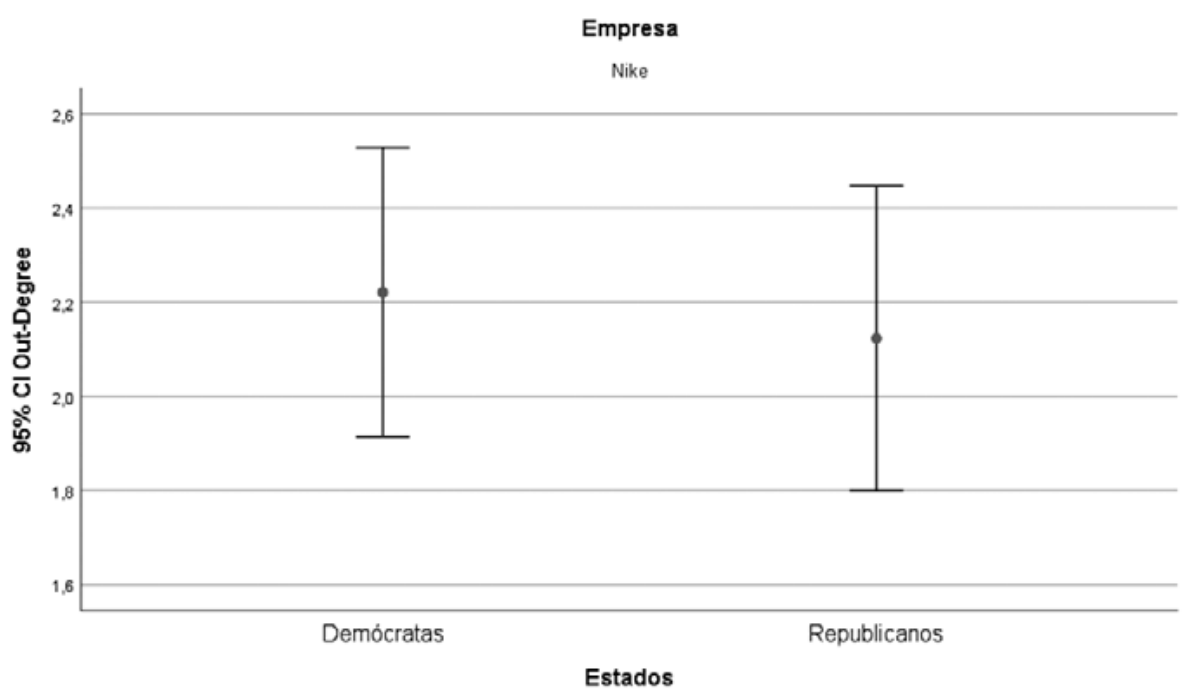

Figura 9. Grado de salida para la red Nike según la influencia política.

Fuente: elaboración propia a partir de los datos de NodeXL Pro. 


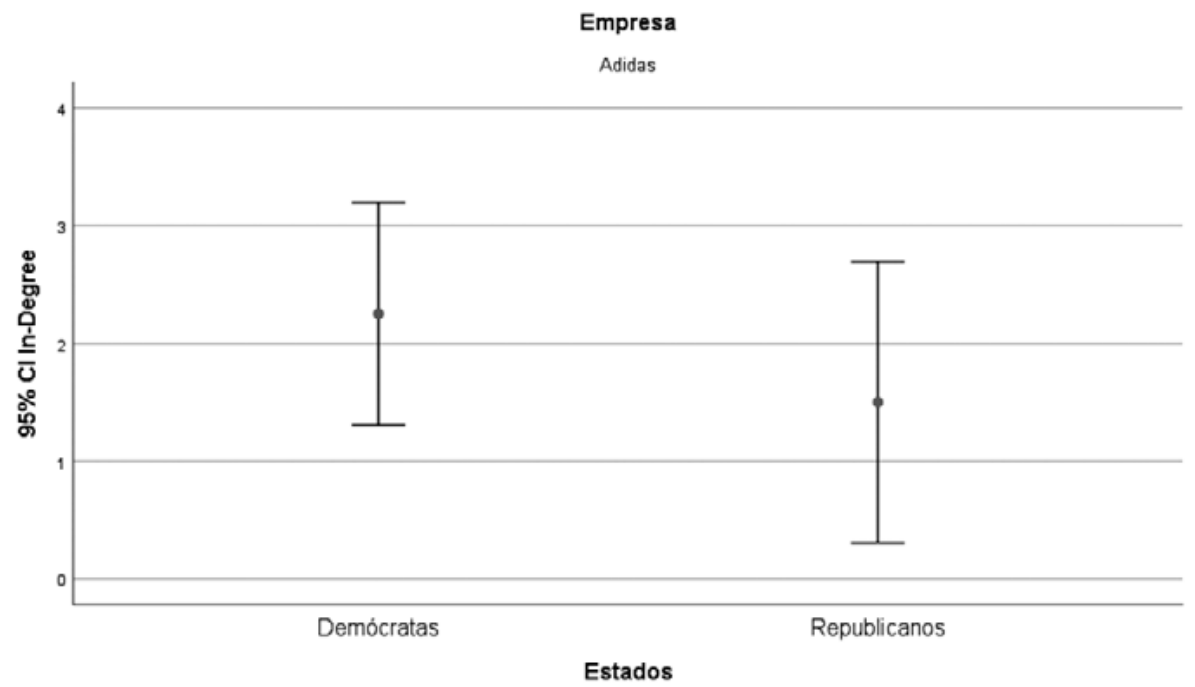

Figura 10. Grado de entrada para la red Adidas según la influencia política.

Fuente: elaboración propia a partir de los datos de NodeXL Pro.

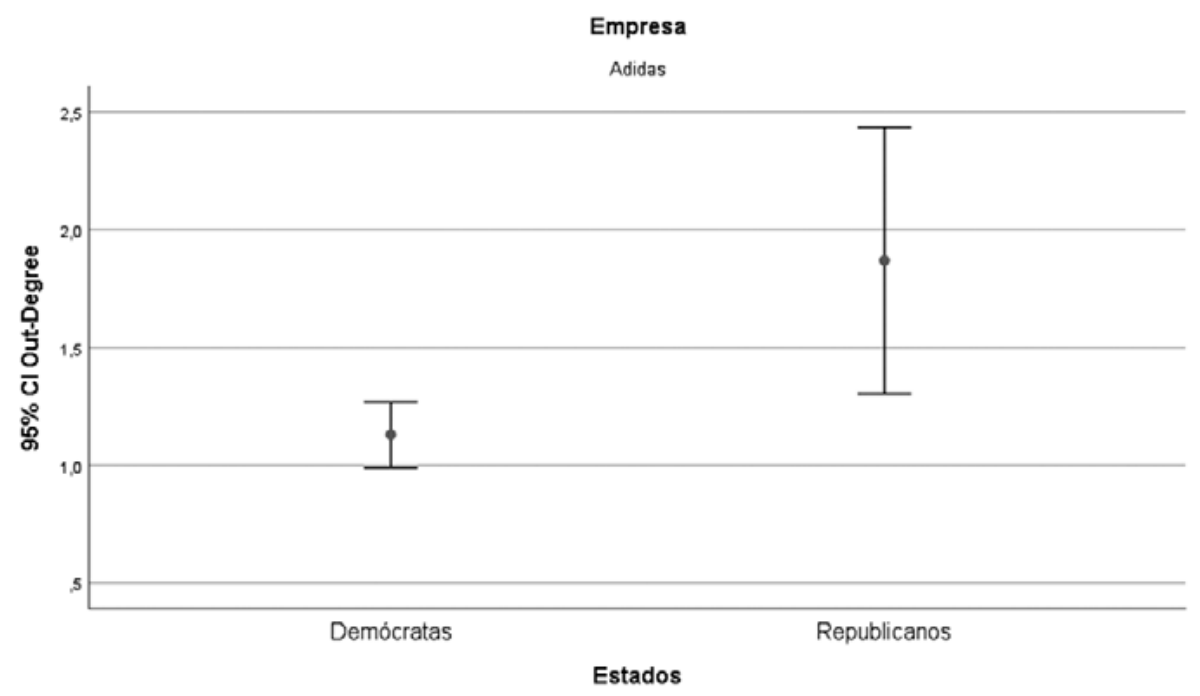

Figura 11. Grado de salida para la red Adidas según la influencia política.

Fuente: elaboración propia a partir de los datos de NodeXL Pro. 
red Adidas se emiten desde los estados republicanos y además abordan la temática productos. En cambio, en la figura 10 no existen diferencias significativas entre las variables, pero, aun así, el promedio de mensajes recibidos es ligeramente superior en los Estados Demócratas.

En definitiva, la estructura conversacional de la red Adidas es la única que varía estadísticamente según los estados desde donde se emitieron los Tuits. Esto permite indicar que, la mayoría de los mensajes enviados en esta red provienen de los estados republicanos abordando la temática productos. En cambio, no ha sido posible demostrar estadísticamente de dónde provienen y a qué estados se envían los mensajes en la red Nike, así como tampoco que los principales debates sobre la responsabilidad social se emitan hacia los estados demócratas. Dado estos fundamentos, no es posible aceptar la Hipótesis 3.

\section{CONCLUSIONES}

Los resultados obtenidos en este estudio indican que ambas redes tienen características distintas. La red Nike cuenta con menor cantidad de aristas y vértices que la red Adidas. Pese a ello, Nike goza de una estructura densa y entrelazada, donde los mensajes fluyen de forma rápida y directa hacia la cuenta de la firma en Twitter. En cambio, en la red Adidas los distintos grupos conversacionales se encuentran más distantes entre sí. Además, los usuarios de la red Adidas se dirigen a diversos usuarios en Twitter, lo cual hace que la información fluya de forma indirecta hacia la marca. Así mismo se ha podido comprobar cómo la red Nike presenta características estructurales de centralidad frente a la red Adidas.

Por otro lado, se hallaron diferencias conversacionales en las redes. Por ejemplo, en Nike son importantes las críticas directas hacia la empresa por su implicación con los distintos grupos sociales, así como su apoyo al movimiento Black Lives Matter. Los mensajes se dirigen en gran medida hacia los estados de simpatía demócrata. Sin embargo, no se han podido corroborar las diferencias estadísticas. En cambio, en el caso de Adidas, sí que se ha podido demostrar cómo predominan los mensajes sobre los productos y cómo estos son emitidos a su vez desde los estados republicanos. Por tanto, se valora como posible desenlace el poder elaborar este estudio de forma longitudinal con una extracción mayor, además de ańadir un estudio sociodiscursivo íntegro. Así mismo se debe tener en cuenta la coyuntura social en la cual se desenvuelven estos debates, así como el contenido que emiten las firmas en sus redes sociales.

Durante el transcurso de una semana, ambas marcas compartieron mensajes sobre sus campañas, así como de apoyo al movimiento BLM. Sin embargo, aunque las dos empresas se han posicionado públicamente contra el racismo en EE. UU., las exigencias de los usuarios sobre ambas no son equiparables. En este sentido, el análisis conversacional demuestra cómo los debates sobre la responsabilidad social empresarial es una cuestión que atañe en mayor dimensión a Nike. Debe señalarse que la empresa es una de las mayores productoras de ropa y calzado a nivel internacional, lo cual le genera un enorme poder de mercado, que a su vez le permite intervenir en 
los regímenes normativos y apostar por un modelo de negocio transparente (Epstein et al., 2010). Por ello, los medios de comunicación se hacen eco de sus acciones, especialmente cuando sus valores pueden verse cuestionados. En consecuencia, las inversiones de Nike para mejorar las condiciones de la comunidad negra en Estados Unidos han causado múltiples opiniones de aprobación y rechazo (NIKE. Inc, 2021e). Por esta razón, durante las revueltas contra el racismo, los mensajes sobre la RSE y en especial la insignia BLM lograban capitalizar la actividad de Nike en la cuenta de Twitter, frente a los mensajes que abordaban la temática productos. Esta estrategia permitía afianzar su propuesta de valor, así como su éxito, el cual quedaba reflejado en el año fiscal 2020 (NIKE. Inc, 2021c). Por ello, los mensajes de la red Nike y la red Adidas son tan distintos, pues pese a que ambos han realizado campańas contra el racismo, su propuesta de valor y por tanto las presiones sobre estas no son las mismas (Vera Martínez, 2008).

Todo ello lleva a cuestionarse: ¿en qué medida es rentable económicamente para Nike mantener una imagen de responsabilidad? Anteriormente, la marca había hecho uso de las estrategias de marketing con causa social y marketing social corporativo, al posicionarse en temas sociales controvertidos. Es por ello por lo que todas estas estrategias, así como sus gastos, se ven reflejados en los informes ejecutivos y fiscales. Por tanto, para responder a esta cuestión se deberá analizar el Informe Ejecutivo y el Informe Fiscal del año 2021, de forma comparativa con los de años anteriores. Cabría prestar especial atención a las variaciones dadas en el año 2020 (Nike. Inc, 2020a) con las del 2021 ha generado sobre esta.

Es preciso destacar, además, la importancia creciente que tiene el análisis de redes sociales en los estudios de prácticas de consumo. En este sentido, la metodología permite conocer el nivel de aceptación que tiene una empresa con sus consumidores, para generar posteriormente estrategias de mercado. Sin embargo, se debe matizar cómo los análisis estructurales de redes sociales virtuales presentan diversas limitaciones, como por ejemplo el tiempo de extracción y el tamaño muestral. NodeXL permite recopilar hasta 18000 tuits de los últimos 9 días. Por lo que, si se desea acceder a las interacciones anteriores, las opciones de búsqueda se limitarán a la red de usuarios de una cuenta de Twitter ${ }^{5}$. La desventaja de esta opción consiste en que la base de datos solo puede utilizarse si la red está abierta para el resto de los usuarios. Otros de los obstáculos encontrados han sido los sistemas de extracción de datos por geolocalización. Aunque la plataforma permite filtrar las búsquedas por países, los datos no solo cuentan en su geolocalización con la información de

${ }^{4}$ El Informe Ejecutivo y el Informe Fiscal de Nike para el año 2021 no se encuentran disponibles.

5 El importador de la red de usuarios de Twitter permite acceder a las cuentas y listas de mensajes de un determinado usuario. Esta función posibilita acceder a 3200 tuits. Además, dependiendo de la actividad del usuario se puede acceder a muchos años de información. La opción permite al analista conocer los patrones de comunicación que presenta un grupo de usuarios (Social Media Reseach Fundation, 2016). 
los estados, sino también de las ciudades, los pueblos e incluso frases o caracteres especiales. Por esta razón es necesario filtrar, depurar y codificar los datos, para obtener mayor cantidad de información verídica de la región que se desea investigar.

Por tanto, a modo de cierre, el conocer las fortalezas y debilidades de este tipo de estudios es fundamental para seguir avanzando en la práctica de esta metodología, así como ampliar los horizontes en los análisis sociológicos sobre la Responsabilidad Social Empresarial.

Recibido: 16 de agosto de 2021; ACEPTAdo: 10 de noviembre de 2021 


\section{REFERENCIAS BIBLIOGRÁFICAS}

Abad Liñan, J.M. y Clemente, Y. (2020, November 21). EE. UU. azul, EE. UU. rojo: Las revelaciones del mapa político de Estados Unidos. El Pais. https://elpais.com/politica/2020/11/18/ sepa_usted/1605721504_544988.html.

Alberich, T. (2014). Movimientos sociales, responsabilidad corporativa e inclusión social en la globalización. Revista Internacional de Sociología, 72(Extra_1), 113-132. https://doi.org/10.3989/ ris.2013.03.04.

Álvarez, E. (2016). Individualismo e identidad humana. Revista Valenciana Estudios de Filosofía y Letras, 3, 37. https://doi.org/10.15174/rv.v0i3.252.

Batista, W.M. (2018). A inferiorização dos negros a partir do racismo estrutural. Revista Direito e Práxis, 9(4), 2581-2589. https://doi.org/10.1590/2179-8966/2018/36867.

Cea Moure, R. (2010). Responsabilidad social corporativa en las entidades bancarias de la Unión Europea. Análisis empírico y propuesta de modelo normalizado [Universidad Autónoma de Madrid]. https://repositorio.uam.es/handle/10486/4183.

Cohen, S. (2020). For Once, Don't Do It': The Powerful Idea Behind Nike's New Anti-Racism Ad. Forbes. https://www.forbes.com/sites/sethcohen/2020/05/30/for-once-dont-do-it---thepowerful-idea-behind-nikes-new-anti-racism-ad/.

Comisión de las Comunidades Europeas. (2001). Libro Verde. Fomentar un marco europeo para la responsabilidad social de las empresas. In Thinking and Reasoning (vol. 7, Issue 2, pp. 121-172). https://www.europarl.europa.eu/meetdocs/committees/deve/20020122/ com(2001)366_es.pdf.

De La Vega Martínez, C. (2020). Ahora o nunca: El poder del Newsjacking desde el contexto publicitario. Pontificia Universidad Javeriana. https://repository.javeriana.edu.co/ handle/10554/52652.

Epstein, M.J., Buhovac, A.R. y Yuthas, K. (2010). Why Nike kicks butt in sustainability. Organizational Dynamics, 39(4), 353-356. https://doi.org/10.1016/j.orgdyn.2010.07.007.

García- Navarro, L. y Davis, W. (2018). How The NFL’s New Rule On Protesting Is Being Perceived By Players. NPR. https://www.npr.org/2018/05/27/614810127/the-nfls-rule-newon-kneeling?t=1617138715561.

García, I., Gibaja, J.J. y Mujica, A. (2001). Marketing Social Corparativo. La respuesta a una demanda social. Estudios Empresariales, 26.32. https://www.econbiz.de/Record/marketing-social-corporativo-la-respuesta-a-una-demanda-social-garcia-iñaki/10006152055.

Hefrron, E. (2019). Nike's Corporate Social Advocacy (CSA) Practices as Related to Strategic Issues Management (SIM) and Threats to Organizational Legitimacy. 2004-2019. https://stars. library.ucf.edu/etd/6502/.

Hendrix, C.S. y Noland, M. (2021). Assessing Potential Economic Policy Responses to Genocide in Xinjiang. 1-20. https://www.piie.com/publications/policy-briefs/assessing-potential-economic-policy-responses-genocide-xinjiang.

Humberstone, J. y Alvarez, F.J. (2019). Análisis de redes sociales: Identificación de comunidades virtuales en Twitter. Realidad y Reflexión, 50(50), 70-81. https://doi.org/10.5377/ryr. v50i50.9095. 
Inofuente Peńaloza, J.E., Turpo Aguilar, J.F., Bargaya Machaca, F.M., Yupanqui Quispe, Y.S. y Ticona Valdivia, O.M. (2021). Segregación Criminal Racial, a partir del caso de George Floyd. Crítica al abuso Del Poder Punitivo. Revista de Derecho, 6(1), 15-50. https:// doi.org/10.47712/rd.2021.v6i1.107.

Justiniano Moreno, D. (2020). Marketing social y responsabilidad social corporativa. Oikos Polis, vol. 5, n. ${ }^{\circ}$ 1, 51-83. http://www.scielo.org.bo/scielo.php?.pid=S2415-22502020000100004\&script $=$ sci_arttext.

Kotler, P. y Zaltman, G. (1971). Social Marketing: An Approach to Planned Social Change. Journal of Marketing, 35(3), 3. https://doi.org/10.2307/1249783.

LA VANGUARDIA (2020). Nike cambia su eslogan tras la muerte de Floyd y Adidas lo comparte. https:// www.lavanguardia.com/deportes/20200531/481523130743/nike-cambia-eslogan-adidas-michael-jordan-george-floyd.html.

Nike. Inc. (2020a). FY20 NIKE, Inc. Impact Report. https://purpose.nike.com/fy20-nike-impact-report.

Nike. Inc. (2020b). FY20 NIKE, Inc. Impact Report-Executive Summary. https://purpose.nike.com/ fy20-nike-impact-report.

Nike. Inc. (2021a). Diversity, Equity \& Inclusion Strategy. https://purpose.nike.com/diversity-equity-inclusion-strategy.

Nike. Inc. (2021b). How we stand up for equality. https://purpose.nike.com/how-we-stand-up-forequality.

NiKe. Inc. (2021c). Impact Portfolio. https://purpose.nike.com/impact-portfolio.

Nike. Inc. (2021d). Nike's New Just Do It Campaign. https://news.nike.com/featured_video/just-doit-dream-crazy-film.

Nike. Inc. (2021e). Our black community commitment. https://purpose.nike.com/our-commitmentto-the-black-community.

Niño-Benavides, T.D.P. y Cortés, M.I. (2018). Comunicación Estratégica y Responsabilidad Social Empresarial, Escenarios y potencialidades en creación De capital social: una revisión de la literarura. Prisma Social, 22, 128-158. https://revistaprismasocial.es/article/view/2570.

Peirón, F. (2021, April 20). El jurado declara culpable al policía Derek Chauvin por la muerte de George Floyd. La Vanguardia. https:/www.lavanguardia.com/internacional/20210420/6986612/ floyd-veredicto-caso-muerte-policia-chauvin-eeuu-juicio.html.

Pintos, J.L. (2004). Inclusión-exclusión. Los imaginarios sociales de un proceso de construcción social. http://hdl.handle.net/10347/4572.

Ramos e Silva, J.A. y Periáñez Cañadillas, I. (2003). Delimitación del Marketing con Causa o Marketing Social Corporativo mediante el análisis de empresas que realizan acciones de responsabilidad social. Cuadernos de Gestion, 3(1-2), 65-82. http://hdl.handle.net/10810/7076.

Recio Mendez, M. (2004). Marketing con causa (Ediciones, pp. 1-9). Planeta de Agostini Profesional y Formación S.L. https://elibro-net.accedys2.bbtk.ull.es/es/ereader/bull/14779?.page=4.

Rivas, O. (2021, April 16). Aumentan más de $50 \%$ asesinatos en siete ciudades de Estados Unidos. PANAM Post. https://panampost.com/oriana-rivas/2021/04/16/aumentan-asesinatos-siete-ciudades-estados-unidos/.

Social Media Reseach Fundation. (2016). Twitter Users Network Importer. https://www.smrfoundation.org/networks/twitter-analytics/. 
Tаводda Campos, M. (2017). Iconografía de la Victoria en la estrategia comunicativa de Nike. http:// repositori.uji.es/xmlui/bitstream/handle/10234/169054/TFG_2017_TaboadaCampos_ Marta.pdf?sequence $=1$ \&isAllowed $=y$.

VARGaS, J.N. (2006). Responsabilidad Social Empresarial (RSE) desde la perspectiva de los consumidores. Comisión Económica Para América Latina y El Caribe-CEPAL, 36. https://repositorio. cepal.org/handle/11362/3543.

Vázquez-Rueda, L., Peraza-Garay, F. de J., Valdivia-Alcalá, R. y López-Leyva, S. (2019). Competitividad interna de las empresas sociales para incrementar su impacto socioeconómico. Estudios Sociales. Revista de Alimentación Contemporánea y Desarrollo Regional, 29(53). https://doi.org/10.24836/es.v29i53.694.

Vera Martínez, J. (2008). Perfil de valor de marca y la medición de sus componentes. Revista Latinoamericana de Administración, 69-89. https://www.redalyc.org/articulo.oa?id=71611842007.

Vidal Liy, M. (2021, March 25). H\&M y Nike afrontan la ira de China por criticar la situación de los uigures en Xinjiang. El Pais. https://elpais.com/internacional/2021-03-25/hm-y-nikeafrontan-la-ira-de-china-por-criticar-la-situacion-de-los-uigures-en-xinjiang.html. 
